\title{
Sistem Pendukung Keputusan Pemilihan Media Cetak Sebagai Sarana Promosi Menggunakan Metode Analytical Hierarchy Process dan Weighted Product
}

\author{
Gunawan $^{1^{*},}$ \\ Teknik Informatika STMIK Balikpapan \\ *Email: gunawan@stmikbpn.ac.id
}

The selection of advertising media in the development and business competition is very important. It determines that criteria and the alternative for each person is different. It makes decisions are very difficult because we have a lot of choices, time and cost.Decisions that are fast and appropriate in determining the best print media as a promotion, which is in accordance with the needs and desires of the advertiser.Selection of Analytical Hierarchy and Weighted Product) method as a tool to assist in making decisions with calculations done by using : Analytical Hierarchy Process to get criteria weight and continue using the WP method. Both methods can provide recommendations in the selection of print media as a medium of promotion.

Keywords : Analytical Hierarchy Process $\quad$ Weighted Product, media print

\begin{abstract}
Abstrak
Pemilihan media iklan dalam pengembangan dan persaingan bisnis menjadi sangat penting, menentukan kereteria dan alternative setiap orang berbeda - beda hal ini menyebabkan keputusan sangat sulit dan memerlukan banyak pilihan, waktu dan biaya keputusan yang cepat dan tepat dalam menentukan media cetak yang terbaik sebagai sarana promosi, yang sesuai dengan kebutuhan dan keinginan dari pemasang iklan. Pemilihan Metode dan Weighted Product dan sebagai alat bantu untuk membantu dalam hal pengambilan keputusan dengan perhitungan di lakukan dengan menggunakan: Analytical Hierarchy Process untuk mendapatkan bobot kreteria dan dilanjut di proses dengan menggunakan metode WP.Kedua metode dapat membantu memberikan rekomendasi dalam pemilihan media cetak sebagai media sarana promosi.
\end{abstract}

Kata kunci : : Analytical Hierarchy Process Weighted Product, media cetak

\section{PENDAHULUAN}

Di era ekonomi kreatif, persaingan bisnis menjadi salah satu yang harus dihadapi oleh para pelaku ekonomi kreatif. Dengan kompetitor atau pesaing yang membuat produk sejenis semakin meningkat sedangkan produk yang dibuat kurang dikenal oleh konsumen membuat pelaku usaha kreatif tidak bisa menjangkau segmen pasar dengan efektif. Agar dapat beradaptasi dengan persaingan antar kompetitor dan mencapai keunggulan kompetitif, produk yang dibuat harus memiliki manfaat kegunaan serta nilai lebih agar dikenal oleh konsumen. Penelitian lain yang mengambil pemilihan percetakan media promosi yang dilakukan oleh Fattya Ariani 2017 tentang Sistem Penunjang Dalam Penentuan Prioritas Pemilihan Percetakan Media Promosi Menggunakan Metode AHP [1]. Penelitian ini dilatar belakangi oleh kebutuhan untuk memperbaiki daya saing atau meningkatnya keunggulan kompetitif organisasi atau perusahaan,sehingga dengan merubah gaya dan cara berbisnis akan suatu 
promosi atau publikasi atas berkembangnya produk dan jasa yang mereka miliki. Adapun penelitian mengenai perbandingan dua metode yang dilakukan

Shiddieq, D., Dan E. Septyan. Dalam "analisis perbandingan metode ahp dan saw dalam penilaian kinerja karyawan (studi kasus di pt. Grafindo media pratama bandung)" hanya membandingkan dua metode Analytical Hierarcy Process dan metode Simple Additive Weighting , Setelah itu menganalisis metode dan melakukan perbandingan dari kedua metode tersebut dengan studi kasus dan dengan begitu didapatlah hasil akhirnya. Hasil skor akhir yang didapatkan dari berbagai perhitungan tidaklah sama, yang menandakan bahwa kematangan dari data yang diolah agar menjadi informasi yang akurat berbeda-beda. Metode SAW lebih banyak digunakan karena proses perhitungannya lebih mudah dipahami, cepat juga simple dibandingkan metode AHP. Sedangkan AHP lebih unggul dalam keakuratan data, karena nilai bobot kriteria tidaklah sembarang ditentukan, melainkan dihasilkan berdasarkan perhitungan[2]

Adapun penelitian lain yang membahas mengenai perbandingan dari dua metode yang dilakukan Febrianita, $\operatorname{dkk}(2015)$ tentang Pemilihan Alternatif Simplisia Menggunakan Metode Weighted Product (WP) dan Metode Simple Additive Weighting (SAW). Proses pemilihan alternatif tersebut dapat dilakukan dengan memanfaatkan Sistem Pendukung Keputusan. Kriteria yang digunakan dalam Sistem Pendukung Keputusan Pemilihan Alternatif Simplisia ini adalah Efek Samping, Harga, Khasiat, Penyediaan Barang serta Rasa. Dan metode yang dipakai adalah perbandingan dari Weighted Product (WP) dan Simple Additive Weighting $(S A W)$, tujuan dari penelitian ini adalah penentuan alternatif simplisia serta menentukan metode terbaik dalam penentuan alternatif simplisia[3]

Dan promosi melalui media cetak masih merupakan cara efektif untuk melakukan pengenalan atau publikasi produk, maka dilakukanlah penelitian untuk merancang sebuah Sistem Penunjang Dalam Penentuan
Prioritas Pemilihan Percetakan Media Promosi. Metode yang digunakan dalam perancangan Sistem Penunjang Keputusan ini adalah metode AHP atau Analytical Hierarchy Process. Dan kriteria yang ditentukan adalah kualitas, harga, estimasi waktu pengerjaan, sistem control, pelayanan, pembayaran dan pengiriman [1

Dalam rangka pengenalan kepada konsumen, strategi yang dapat dilakukan oleh pelaku usaha kreatif adalah dengan melakukan promosi atau periklanan, baik itu dengan media elektronik, media cetak, maupun media outdoor. Penggunaan bermacam-macam media promosi merupakan salah satu cara yang digunakan oleh pelaku ekonomi kreatif untuk melakukan promosi untuk memperkenalkan usaha mereka. Media cetak merupakan media yang saat ini masih di gunakan sebagai serana promosi usaha, kelibihan media cetak adalah :

1. Dari segi harga, slot iklan di media cetak lebih murah dibandingkan dengan harga iklan media televisi.

2. Iklan media cetak memiliki berbagai macam bentuk, baik ukuran display, warna halaman display iklan, dan nomor halaman. Sementara khusus iklan di majalah, variasi iklan juga dapat dikelompokkan berdasarkan jenis kertas tempat display iklan.

3. Sasaran iklan akan lebih tersegmentasi terutama iklan majalah dan tabloid karena majalah dan tabloid umumnya memiliki tema khusus dan segmen pasar tertentu.

4. Waktu memperhatikan iklan lebih besar di media cetak dibandingkan dengan media televisi. Karena iklan media televisi mahal dan umumnya berdurasi 30 detik, maka pesan yang disampaikan harus singkat dan menarik. Sementara di media cetak, audiens mempunyai keleluasaan untuk memperhatikan iklan dalam waktu lebih lama.

5. Dapat digunakan sekaligus sebagai sarana promosi penjualan, seperti pemberian kupon, voucher diskon belanja, sampel produk, bonus, dan lain-lain. Majalah mempunyai kemampuan mengangkat 
produk-produk yang diiklankan sejajar dengan persepsi khalayak terhadap prestise majalah yang bersangkutan.

\section{METODOLOGI}

\section{Multi Attribute Decision Making}

Multi Attribute Decision Making adalah suatu metode pengambilan keputusan yang digunakan untuk menetapkan alternatif terbaik dari sejumlah alternatif yang ada berdasarkan beberapa kriteria tertentu yang telah ditentukan. Inti dari Multi Attribute Decision Making (MADM) adalah menentukan nilai bobot untuk setiap atribut kriteria, kemudian dilanjutkan dengan proses perankingan yang akan menyeleksi alternatif yang telah diberikan.

Tahapan Multi Attribute Decision Making (MADM) Proses dari MADM ini dilakukan melalui 3 tahapan yaitu[4]:

1. Pada tahapan penyusunan komponen situasi, akan dibentuk tabel taksiran yang berisi indentifikasi alternatif dan spesifikasi tujuan, kriteria dan atribut.

2. Pada tahapan analisis dilakukan melalui dua langkah yaitu:

a. Mendatangkan taksiran dari besaran potensial, kemungkinan, dan ketidakpastian yang berhubungan dengan dampak-dampak yang mungkin pada setiap alternatif.

b. Melakukan pemilihan dari preferensi pengambilan keputusan untuk setiap nilai dan ketidakpedulian pada setiap resiko yang timbul.

3. Kemudian dilakukan tahap sintesis informasi.

Sistem Pendukung keputusan merupakan system informasi interaktif yang menyediakan informasi, pemodelan dan pemanipulasian data. Sistem itu digunakan untuk membantu pengambilan keputusan dalam situasi yang semiterstruktur dan situasi yang tidak terstruktur, dimana tidak seorang pun tahu secara pasti bagaimana keputusan seharusnya). Komponen Sistem Pendukung Keputusan

Aplikasi sistem pendukung keputusan bisa terdiri dari beberapa subsistem [4], yaitu:
1. Sub sistem manajemen data: Sub sistem manajemen data memasukkan satu database yang berisi data yang relevan untuk situasi dan dikelola oleh perangkat lunak yang disebut system manajemen basisdata (Data Base Management System). Subsistem manajemen data bisa diinterkoneksikan dengan data warehouse perusahaan, suatu repository untuk data perusahaan yang relevan dengan pengambilan keputusan.

2. Sub sistem manajemen model : Merupakan paket perangkat lunak yang memasukkan model keuangan, statistik, ilmu manajemen, atau model kuantitatif lain yang memberikan kapabilitas analitik dan manajemen perangkat lunak yang tepat. Bahasa-bahasa pemodelan untuk membangun model-model kustom juga dimasukkan. Perangkat lunak itu sering disebut system manajemen basis model (MBMS). Komponen tersebut bisa dikoneksikan ke penyimpanan korporat atau eksternal yang ada pada model.

3. Sub sistem antarmuka pengguna : Pengguna berkomunikasi dan memerintahkan system pendukung keputusan melalui subsistem tersebut. Pengguna adalah bagian yang dipertimbagkan dari system. Para peneliti menegaskan bahwa beberapa kontribusi untuk dari system pendukung keputusan berasal dari interaksi yang intensif antara computer dan pembuat keputusan..

Decision Support System (DSS) atau Sistem Pendukung Keputusan (SPK) merupakan sebuah sistem yangdimaksudkan untuk mendukung para pengambil keputusan manajerial dalam situasi keputusan semiterstruktur[1].

Decision Support System and Intelligent System(DSS) [1], mendefinisikan Decision Support System sebagai sekumpulan prosedur berbasis model untuk data pemrosesan dan penilaian guna membantu para manajer mengambil keputusan.

Tujuan dari Sistem Pendukung Keputusan adalah: 
1. Membantu manajer dalam pengambilan keputusan atas masalah semi terstruktur

2. Memberikan dukungan atas pertimbangan manajer dan bukannya dimaksudkan untuk menggantikan fungsi manajer.

3. Meningkatkan efektivitas keputusan yang diambil manajer lebih pada perbaikan efisiennya.

4. Kecepatan komputasi. Komputer memungkinkan para pengambil keputusan untuk melakukan banyak komputasi secara cepat dengan biaya rendah

5. Peningkatan produktivitas. Membangun satu kelompok pengambil keputusan, teutama para pakar.

6. Dukungan kualitas. Komputer bisa meningkatkan kualitas keputusan yang dibuat.

7. Berdaya saing. Manajemen dan pemberdayaan sumber daya perusahaan. Tekanan persaingan menyebabakan tugas pengambilan keputusan menjadi sulit.

8. Mengatasi Keterbatasan kognitif dalam pemrosesan dan penyimpanan.

\section{Analytical Hierarcy Process}

Analytical Hierarcy Process (AHP) adalah salah satu metode khusus dari Multi Criteria Decision Making (MCDM) yang diperkenalkan oleh Thomas L. Saaty. AHP sangat berguna sebagai alat dalam analisis pengambilan keputusan dan telah banyak digunakan dengan baik dalam berbagai bidang. Pada dasarnya, metode AHP memecah-mecah suatu situasi yang kompleks dan tak terstruktur ke dalam bagian-bagian komponennya.

Dalam menyelesaikan permasalahan dengan AHP ada beberapa prinsip yang harus dipahami, yaitu:

1. Membuat hirarki

2. Penilaian kriteria dan alternatif

Kriteria dan alternatif dilakukan dengan perbandingan berpasangan untuk bebagai persoalan skala 1 sampai 9 adalah sekala terbaik untuk menekspresikan pendapat.sesuai tabel 1 :

Tabel 1. Intensitas Kepentingan.

\begin{tabular}{|c|c|c|}
\hline No & Intensitas & keterangan \\
\hline 1 & 1 & $\begin{array}{l}\text { Kedua elemen sama } \\
\text { pentingnya }\end{array}$ \\
\hline 2 & 3 & $\begin{array}{l}\text { Elemen yang satu sedikit } \\
\text { lebih penting }\end{array}$ \\
\hline 3 & 5 & $\begin{array}{l}\text { Elemen yang satu lebih } \\
\text { penting }\end{array}$ \\
\hline 4 & 7 & $\begin{array}{l}\text { Elemen yang satu sangat } \\
\text { penting }\end{array}$ \\
\hline 5 & 9 & $\begin{array}{l}\text { Elemen yang satu mutlak } \\
\text { penting }\end{array}$ \\
\hline 6 & $2,4,6,8$ & $\begin{array}{l}\text { Nilai - nilai antara dua nilai } \\
\text { pertimbangan - } \\
\text { pertimbangan yang } \\
\text { berdekatan }\end{array}$ \\
\hline
\end{tabular}

3. Menentukan prioritas

Untuk setiap kriteria dan alternatif, perlu dilakukan perbandingan berpasangan. Nilai - nilai perbandingan relatif dari seluruh alternatif kriteria bisa disesuaikan dengan judgment yang telah ditentukan untuk menghasilkan bobot dan prioritas. Bobot dan prioritas dihitung dengan mamanipulasi matriks atau melalui penyelesaian persamaan matematika

4. Konsitensi logis

Konsistensi logis memiliki dua makna. Pertama objek - objek yang serupa bisa dikelompokkan sesuai dengan keseragaman dan relevansi. Kedua, menyangkut tingkat hubungan antar objek yang didasarkan pada kriteria tertentu, Tahapan perhitungan perbandingan kreteria menggunakan metode Analytical Hierarcy Process (AHP) merujuk padaDalam tabel 2.

Tabel 2. Matriks Perbandingan kreteria Berpasangan

\begin{tabular}{cccccc} 
NO & Kreteria & Harga & Radius & $\begin{array}{c}\text { Hala } \\
\text { man }\end{array}$ & Oplah \\
\hline 1 & Harga & 1 & 3 & 2 & 5 \\
2 & Radius & 0,33 & 1 & 2 & 1 \\
3 & Halaman & 0,50 & 0,500 & 1 & 3 \\
4 & Oplah & 0,200 & 1 & 0,33 & 1 \\
\hline
\end{tabular}


Menghitung hasil perkalian masingmasing pada setiap baris elemen dan $\mathrm{n}$ akar pangkat, rumus yang digunakan dapat dilihat pada persamaan

$$
\overline{W_{l}}=\sqrt[n]{\prod_{j=1}^{n} a_{i j}}
$$

Jumlah vector $W i=(\overline{W 1}, \overline{W 2}, \ldots, \overline{W n})^{t}$, untuk proses normalisasi dapat dilihat pada persamaan

$$
W i=\frac{\overline{W_{l}}}{\sum_{i=1}^{n} \bar{W}_{l}}
$$

Tahapan selanjutnya menghitung nilai $\lambda$ maks dari matriks perbandingan. Rumus untuk mencari nilai $\lambda$ maks sesuai dengan persamaan:

$$
\lambda \max =\sum_{i=1}^{n} \sum_{j}^{n} a_{i j} W_{j}
$$

Menghitung consistency indeks dapat dilihat pada persamaan :

$$
\mathrm{CI}=\frac{(\lambda \text { maks }-\mathrm{n})}{(\mathrm{n}-1)}
$$

Menghitung consistency ratio (CR) dapat dilihat pada persamaan berikut :

$$
\mathrm{CR}=\frac{\mathrm{CI}}{\mathrm{RI}}
$$

Tabel 3. Nilai Random Konsistensi

\begin{tabular}{ccc}
\hline NO & $\begin{array}{c}\text { Ukuran } \\
\text { Matriks (n) }\end{array}$ & Nilai RI \\
\hline 1 & 1 & 0 \\
2 & 2 & 0 \\
3 & 3 & 0.58 \\
4 & 4 & 0.90 \\
5 & 5 & 1.12 \\
6 & 6 & 1.24 \\
7 & 7 & 1.32 \\
8 & 8 & 1.41 \\
9 & 9 & 1.45 \\
10 & 10 & 1.49 \\
\hline
\end{tabular}

\section{Weighted Product}

Metode Weighted Product ( WP ) merupakan salah satu metode penyelesaian masalah MADM atau Multi Attribute DecissionMaking. Metode ini melakukan evaluasi alternatif terhadap kriteria, dan melakukan perhitungan dari evaluasi tersebut dengan bobot kriteria yang ada. Metode ini menggunakan perkalian untuk menghubungkan rating atribut, dimana rating setiap atribut harus dipangkatkan dulu dengan bobot yang bersangkutan. Proses ini sama halnya dengan proses normalisasi[1].

Tahapan Perhitungan Weighted Product Tahapan perhitungan permodelan menggunakan metode Weighted Product yaitu:

1. Normalisasi bobot kriteria

Normalisasi bobot kriteria dilakukan untuk mengetahui nilai perbandingan antar kriteria yang ada. Normalisasi bobot kriteria dilakukan dengan menggunakan persamaan.

$$
\begin{gathered}
W_{j} \mathrm{j}_{-} \mathrm{w}_{-} \mathrm{j} /\left(\sum \sum_{\text {W.: }} \mathrm{w}_{-} \mathrm{j}\right) \\
W_{j}=\frac{w_{j}}{\sum w_{j}}
\end{gathered}
$$

Normalisasi bobot kriteria dilakukan dengan membagi nilai bobot dengan jumlah bobot kriteria yang ada, dimana :

$w_{j}=$ nilai bobot kriteria.

$\sum w_{j}=$ jumlah bobot kriteria.

\section{Menghitung Vektor $S$}

Nilai Vektor $\mathrm{S}$ pada metode Weighted Product didapatkan dengan persamaan

$$
S_{i}=\prod_{j=1}^{n} x_{i j}{ }^{W_{j}}
$$

Variabel $w$ bernilai positif untuk kriteria benefit dan bernilai negative untuk kriteria cost. Dengan $i=1,2, \ldots$, dst dan $j=1,2, \ldots$ n, dimana:

$\Pi=$ product $/$ jumlah kali.

$S_{i}=$ skor / nilai dari setiap alternatif.

$x_{i j}=$ nilai alternatif $\mathrm{ke}-i$ terhadap atribut ke-j. 


$$
\begin{aligned}
W_{j}= & \text { Bobot dari setiap atribut atau } \\
& \text { kriteria. } \\
n= & \text { Skor } / \text { nilai dari setiap alternatif. }
\end{aligned}
$$

\section{Menghitung Vektor V}

Proses perhitungan Vektor V metode Weighted Product dapat dilihat pada persamaan

$$
V_{i}=\frac{S_{i}}{\prod_{j}^{n}=1\left(x_{j}^{*}\right)^{w_{j}}}
$$

Nilai Vektor $\mathrm{V}$ dari masing masing alternatif, dijadikan acuan perangkingan dari alternatif yang terdaftar, dimana $V=$ Preferensi alternatif.

$W=$ Bobot kriteria.

$\mathrm{I}=$ Alternatif.

$\mathrm{J}=$ Kriteria

$n=$ Banyak kriteria

* = Banyak kriteria yang telah dinilai pada vektor

Penentuan nilai preferensi setiap alternatif yang dilakukan pada metode SAW dapat dilihat pada persamaan:

$$
V_{i}=\sum_{j=1}^{n} w_{j} r_{i j}
$$

Pada Gambar 1 ini akan diuraikan metode yang akan digunakan, sumber data yang dibutuhkan dan metode pengumpulan data yang digunakan untuk menjelaskan proses pengambilan dan pencarian data.

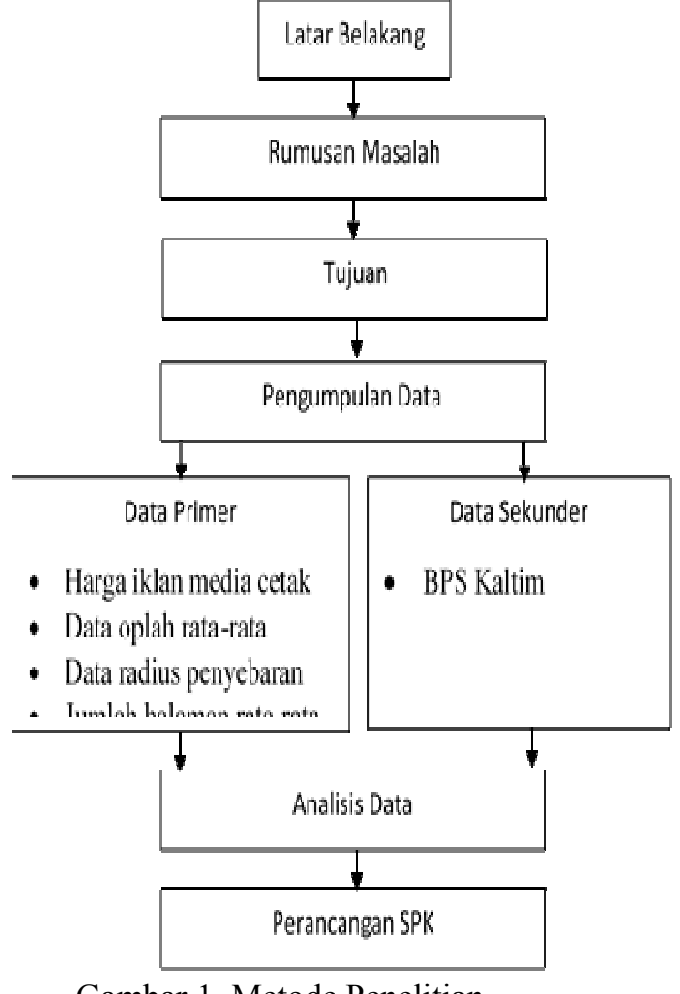

Gambar 1. Metode Penelitian

\section{Metode Perancangan}

Metode perancangan yang digunakan untuk mengambarkan proses yang diusulkan dalam penelitian ini adalah Use Case DiagramUse case menjelaskan tentang urutan kegiatan yang dilakukan oleh actor dan system untuk tercapainya suatu tujuan tertentu. Didalam use case ini selain menjelaskan kegiatan namun juga menjelaskan apa yang di lakukan oleh actor terhadap systembagian ini akan dijelaskan gambaran mengenai penggunaan sistem beserta proses dan entitas pengguna didalamnya pada gambar 2 . 


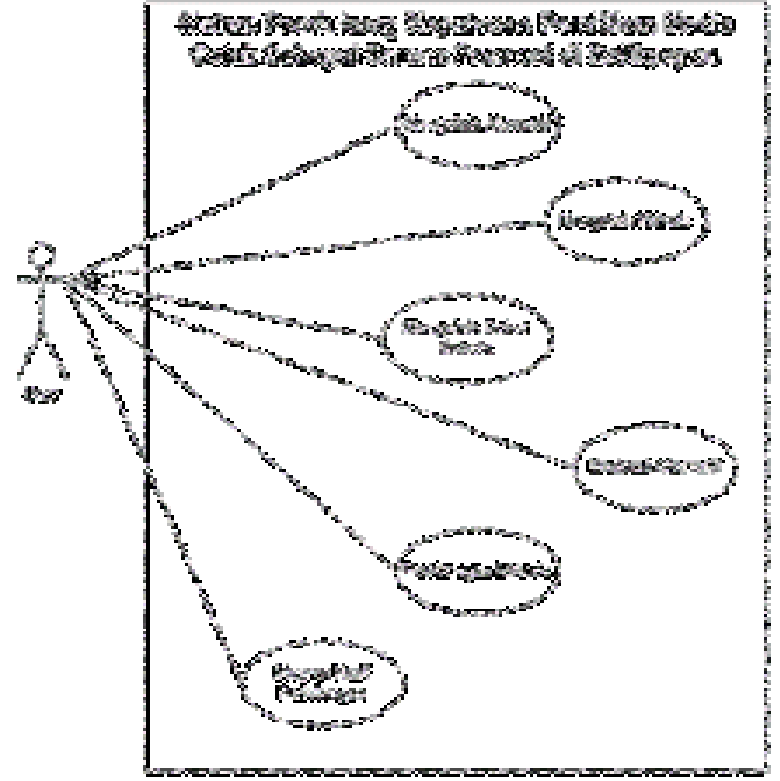

Gambar 2. Use Diagram

\section{Alur Proses Perancangan aplikasi}

Peneliti melakukan langka-langkah penelitian yang sesuai dengan alur dengan memgabungakan dua metode Analytical Hierarcy Process dan Metode Weighted Product.

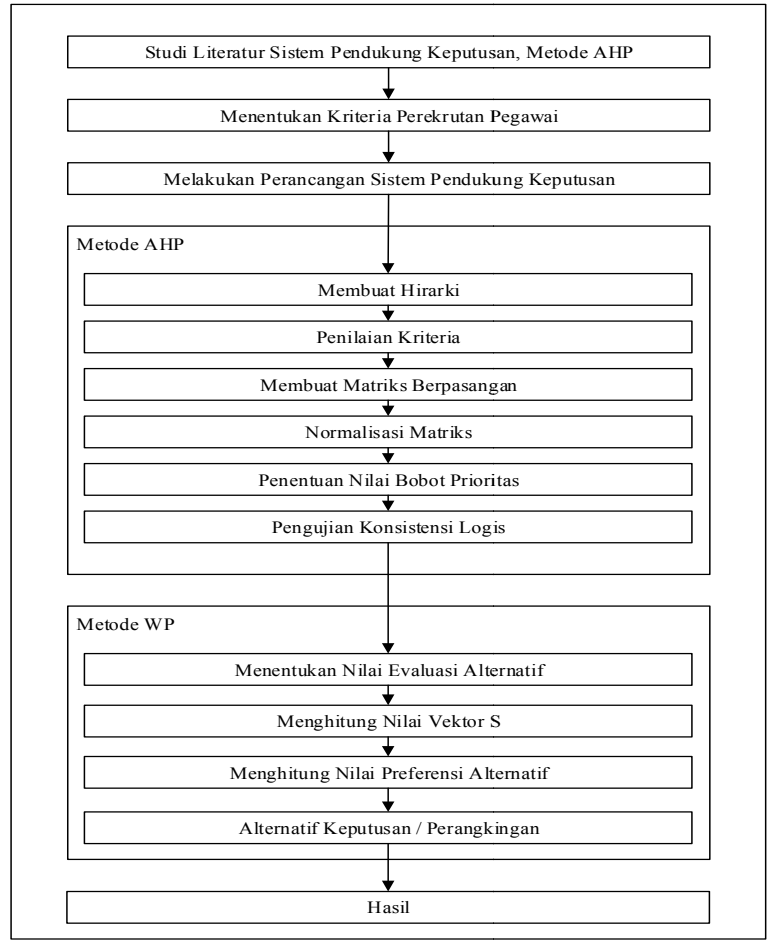

Gambar 3. Alur proses

\section{Implementasi dan Pengujian}

Berdasarkan hasil wawancara dan kumpulan data primer, data sukender dan perhitungan dengan metode AHP dari pihak terkait di jelaskan dalam table 4 dan tabel 5 .

Tabel 4. Bobot kreteria

\begin{tabular}{llll}
\hline No & Kriteria & Type & Bobot \\
\hline 1 & Harga & cost & 0,385 \\
2 & Radius + & benefit & 0.142 \\
3 & Halaman & benefit & 0.087 \\
4 & Oplah & Benefit & 0,385 \\
\hline
\end{tabular}

Tabel 5. Matrik Data alternative

\begin{tabular}{cccccc}
\hline $\begin{array}{c}\text { N } \\
\text { o }\end{array}$ & $\begin{array}{c}\text { Medi } \\
\text { a }\end{array}$ & $\begin{array}{c}\text { Harg } \\
\text { a }\end{array}$ & $\begin{array}{c}\text { Radiu } \\
\text { s }\end{array}$ & Hal & Oplah \\
\hline 1 & MKP & 40800 & 2838 & 40 & 97000 \\
2 & M BP & 18000 & 2461 & 19 & 32000 \\
3 & MTK & 25200 & 3178 & 32 & 60235 \\
4 & MKK & 19200 & 2838 & 28 & 30000
\end{tabular}

Hasil perhitungan Nilai Vektor $\mathrm{V}$ dan Vektor S dengan metode WP dari masing masing alternatif, dijadikan acuan perangkingan dari alternatif ditunjukan di tabel 6

Tabel 6. Hasil Perhitungan Metode WP

\begin{tabular}{ccccc}
\hline No & $\begin{array}{c}\text { Nama } \\
\text { Media }\end{array}$ & $\begin{array}{c}\text { Vektor } \\
\text { S }\end{array}$ & $\begin{array}{c}\text { Vektor } \\
\text { V }\end{array}$ & Rank \\
\hline 1 & M KP & 10.7049 & 0.2760 & 1 \\
2 & M BP & 8.5510 & 0.2205 & 4 \\
3 & M TK & 10.6480 & 0.2746 & 2 \\
4 & M KK & 8.8749 & 0.2289 & 3 \\
\hline
\end{tabular}

Hasil perhitungan Normalisasi table dan perkalian bobot kreteria dengan metode WP dari masing masing alternatif, dijadikan acuan 
perangkingan dari alternatif ditunjukan di tabel 4

Tabel 7. Hasil Perhitungan metode WP

\begin{tabular}{cccc}
\hline No & $\begin{array}{c}\text { Nama } \\
\text { Media }\end{array}$ & $\begin{array}{c}\text { Vektor } \\
\text { V }\end{array}$ & Ranking \\
\hline 1 & Media KP & 0.386 & 1 \\
2 & Media BP & 0.168 & 4 \\
3 & Media TK & 0.266 & 2 \\
4 & Media KK & 0.178 & 3 \\
\hline
\end{tabular}

\section{HASIL DAN PEMBAHASAN}

Pengujian Aplikasi

Pada tahap ini pembuatan aplikasi yang telah diimplementasikan akan diuji untuk mengenai tingkat keberhasilan.Setelah dilakukan tahap implementasi terhadap pengguna sehingga dapat diketahui sejauh mana aplikasi dapat memudahkan pengguna ketika digunakan gambar 4 menunjukan tampilan depan yang mengambar keadaan hasil pemenang media cetak secara langsung jika ada perubahan data

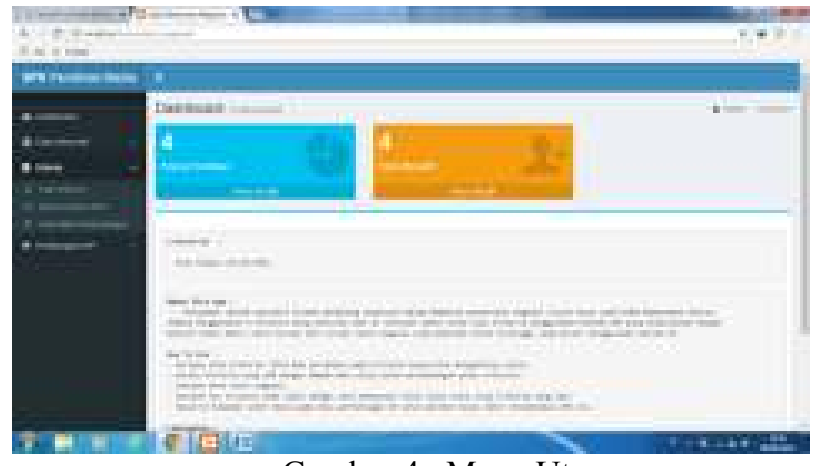

Gambar 4. Menu Utama

Hasil akhir pengujian dua metode Analytical Hierarcy Process dan metode Weighted Productdalam pengambilan keputusan untuk media cetak sebagai sarana promosi di tunjukan dalam Gambar 5

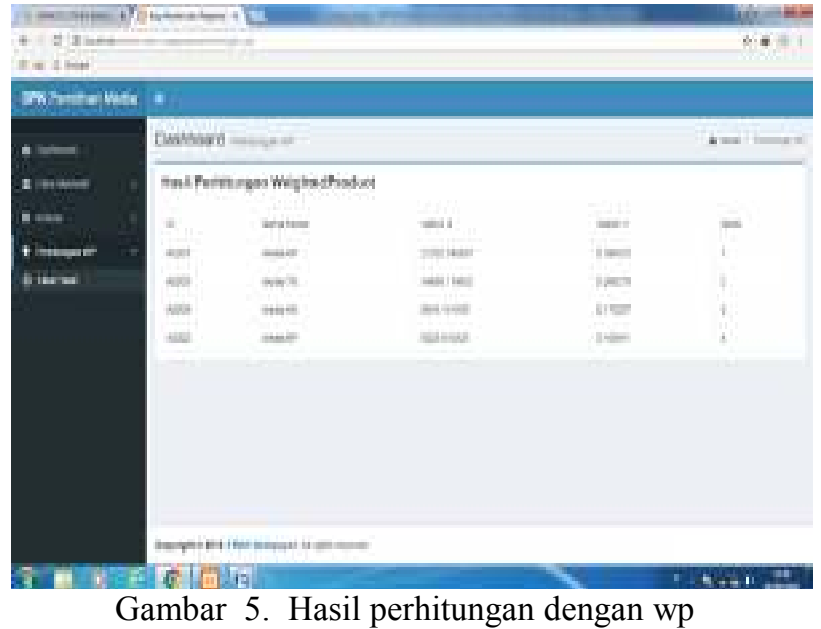

\section{KESIMPULAN}

Berdasarkan penelitian dan pengujian diatas, maka diperoleh : bahwa dalam penerapan metode Analytical Hierarcy Processdalam proses pembobotan kreteria dan dilanjutkan dengan metodeWeighted Product maka:

1. Sistem pendukung keputusan pemilihan media cetak dapat membantu manajer dalam menetukan media yang akan digunakan dalam media promosi yang efektif dan efesien.

2. Berdasarkan hasil pengujian yang sudah dilakukan dengan menggunakan metode black box maka dapat disimpulkan bahwa sistem yang dibangun dapat bekerja sesuai dengan fungsi yang diharapkan

\section{SARAN}

Diperlukan adanya penelitian lebih lanjut. Dan lebih banyak kreteria dalam menentukan pilihan media cetak, memadukan metode yang lain dalam proses pendukung keputusan.

\section{DAFTAR PUSTAKA}

[1] Fattya,A., 2017, "Sistem Penunjang Dalam Penentuan Prioritas Pemilihan Percetakan Media Promosi Menggunakan Metode AHP", Jurnal Informatika,Volume 4 No.2 September 2017 pp 214-221. 
[2] Shiddieq, D., Dan E. Septyan 2017, "Analisis perbandingan metode ahp dan saw dalam penilaian kinerja karyawan (studi kasus di pt. Grafindo media pratama bandung)". Jurnal Komputer Bisnis, Vol. 10, No. 2, Dec. 2017, p/125 $-130$

[3] Febrianita,I,Arief,A,Nurul,H.,2015, Pemilihan Alternatif Simplisia Menggunakan Metode Weighted Product (WP) dan Metode Simple Additive Weighting (SAW), JEEST, Vol. 02 No. 01, July 2015, pp 20-30

[4] [Kusumadewi,S., 2006, Fuzzy MultiAttribute Decision Making (FUZZY MADM), Penerbit Graha Ilmu, Yogyakarta

[5] Turban, E., J. E. Aronson, T. Liang, 2005, Sistem Pendukung Keputusan dan Sistem Cerdas, Andi Offset, Yogyakarta. 